\title{
Research on the Marketing Status and Countermeasures of Small Pieces of Creative Ceramics in Jingdezhen: Based on the Perspective of Consumer Psychology
}

\author{
Ling Guo ${ }^{1, a}$ and Yanwei Zhao ${ }^{2, b}$
}

\author{
${ }^{1}$ The Department of Law and Business of College of Technology and Art Jingdezhen Ceramic \\ Institute, China \\ ${ }^{2}$ The Department of Law and Business of College of Technology and Art Jingdezhen Ceramic \\ Institute, China \\ a33837770@qq.com, ${ }^{b} 109674495 @ q q . c o m$
}

Keywords: Jingdezhen; Creative Ceramic; Marketing; Consumer Psychology

\begin{abstract}
In order to adapt to the social development, Jingdezhen' artist joined some new elements into the traditional ceramic art to create a new type of cultural creative industries--creative ceramics industry, the rise of this new cultural creative industry in Jingdezhen has a profound impact. Based on the interview and questionnaire survey on the present situation of Jingdezhen small pieces of creative ceramics products, this paper analyzes the factors that affect consumers' purchase and their own factors, and puts forward some suggestions from the original innovation, broadening the propaganda channel and increasing the protection of intellectual property right, in order to promote the sustainable development of Jingdezhen small pieces of creative ceramics industry.
\end{abstract}

\section{Introduction}

Under the accumulation of porcelain making history in 1700, Jingdezhen has a unique ceramic culture and ceramic art with oriental art. Creative ceramic products are integrated into the designer's unique ideas. It is a product that combines traditional ceramic art with modern technology, culture, thought, trend and aesthetics. It has high added value, high creativity and high circulation.

The production process of ceramic creative products and creative services is the inheritance, research and protection of traditional ceramic culture. Through the operation of the industry, the integration and utilization of regional ceramic cultural resources can be accelerated, and the ceramic culture with a glorious and long Chinese culture is spread to the global consumers.[1]

\section{The Present Situation of Small Pieces of Creative Ceramics in Jingdezhen}

Types of small pieces of creative ceramic products. Jingdezhen small pieces of creative ceramics mainly have four categories: ornament ceramics, daily use ceramics, gift ceramics and decoration ceramics. According to the survey, $32.14 \%$ of daily ceramics were consumed by consumers, $35.71 \%$ of gift ceramics, $17.86 \%$ of ornament ceramics, $62.5 \%$ of decoration ceramics.

Price of small pieces of creative ceramics. The retail price of small pieces of creative ceramic ornaments in Jingdezhen creative market ranges from 10 yuan to 100 yuan, and the wholesale price is 1 to 5 yuan lower than the market price. The creative ceramic products of daily use, decoration and gift range from 60 to 300 yuan, and the wholesale price is 5 to 15 yuan lower than the market price.

Consumers' sources of information for small pieces of creative ceramic products. According to the survey results (Fig. 1), the channels for consumers to know small pieces of creative ceramics are mainly friends and shopping. From this, it can be seen that the propaganda of Jingdezhen small pieces of creative ceramics products mainly depends on the mouth of the consumers, and most of the sellers are giving the business card to the consumers when they buy it to achieve the role of propaganda. 


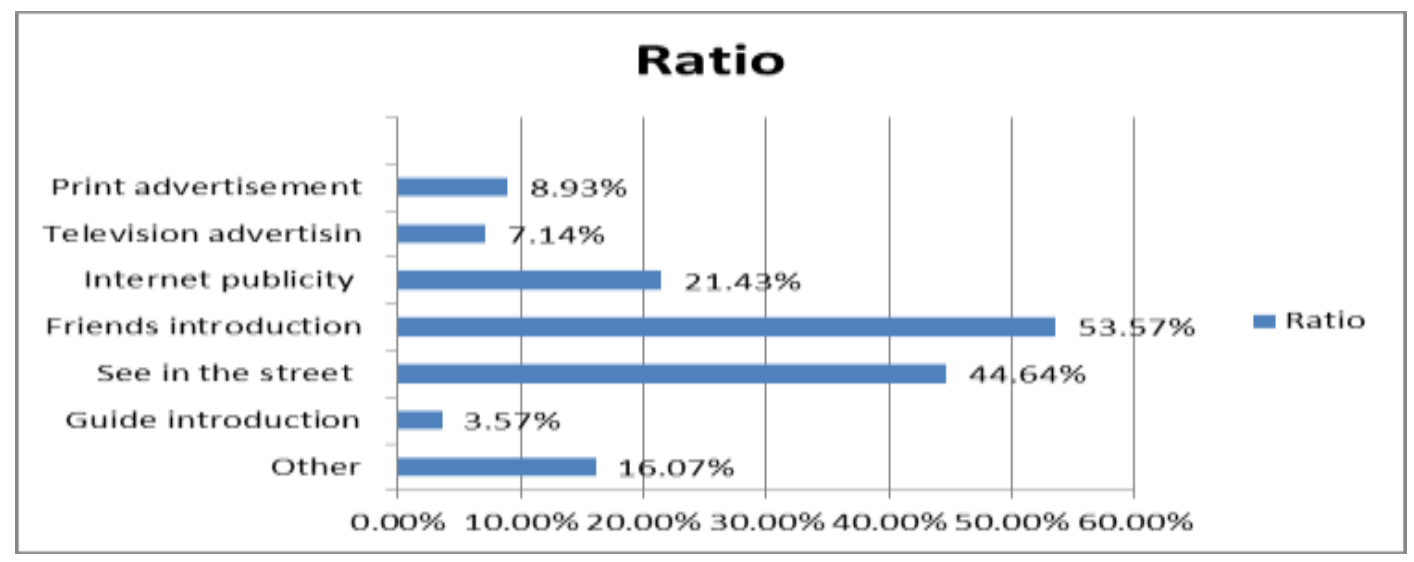

Figure 1 The creative ceramic information source for consumer collection

Places for small pieces of creative ceramics. Relying on rich resources of ceramic culture, Jingdezhen has already existed more than 5000 cultural and creative porcelain entities, mainly through the development of "company + studio" model, manual workshop model and so on. [2]The sales form of Jingdezhen small pieces of creative ceramics is mainly based on sales of shops and small stalls. Small pieces of creative ceramics stalls are mainly concentrated in the creative market. Creativity and fun are the unique features of these fairs. The number of ceramic products in the market is not much, but there are many kinds.[3]

Jingdezhen small pieces of creative ceramics consumers choose to buy ceramic products in some ceramic creative parks, such as the creative market of Jingdezhen sculpture porcelain factory, Tao Xichuan Ceramic Cultural Industry Park and so on, and then purchase through network.

\section{Analysis of Consumers' Influence Factors on Purchasing Small Pieces of Creative Ceramic Products}

Features of small pieces of creative ceramics. According to the survey results (Fig. 2), consumers prefer creative ceramic products with fashionable personality, simplicity, retro style, landscape and pastoral style in the Jingdezhen market. According to the survey, the most important factor for consumers to buy creative ceramic products is appearance, followed by creative factors, followed by product quality. From this we can see that consumers' demand for "beauty" of creative ceramics is getting higher and higher.

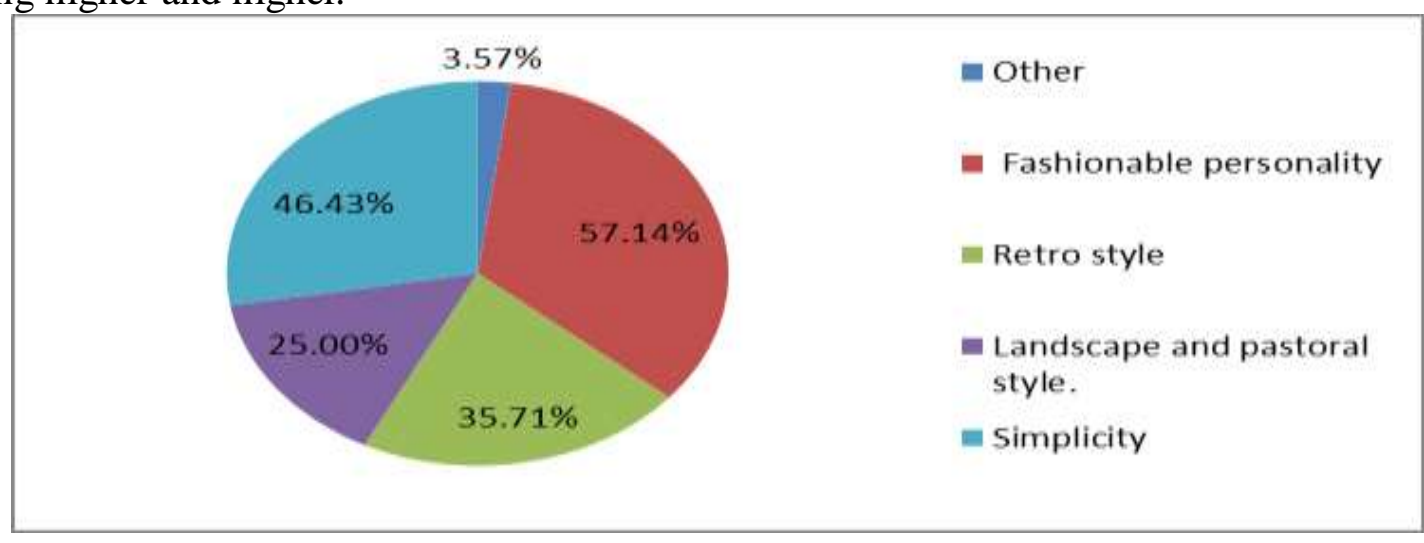

Figure 2 Small creative ceramic style of consumer preference

The price range of the small pieces of creative ceramics that most consumers are willing to pay is between 51 and 100 yuan. 26.79\% of the consumers want to buy creative ceramics below 50 yuan, and the minority are willing to pay more than 101 yuan.

We can find out that the appearance, creativity, quality and practicality of Jingdezhen small creative ceramics are the main factors to attract consumers, and consumers are more willing to buy products that are not very expensive. Although some consumers will be affected by others in their 
consumption, most consumers are most concerned with the factors of the product itself when buying creative ceramics.

Analysis of the characteristics of consumers. According to the survey, the young consumers aged from 19 to 29 in the Jingdezhen market are more inclined to decorate ceramics and ornament ceramics on the type of small creative ceramics. The middle-aged consumers from 30 to 49 years old tend to give preference to gift ceramics and decorate ceramics, and the older consumers over the age of 50 have a unique feeling for the gift ceramics.

When buying small creative ceramic products, young consumers are more likely to be affected by product's own factors, price, opinions of family and friends and the service attitude of the Sellers; middle aged consumers are less sensitive to product prices compared with younger consumers, and the impact of family and friends' opinions on the olderly consumer group is not very large.

According to the survey results, consumers with higher economic level (more than 6000 yuan per month) are more concerned about the symbolic value and cultural significance of products. In the middle class (between 2001 and 6000 yuan per month), the consumers are more likely to pursue the best price performance of their products. For poor consumers, the most important aspect is their use value and actual efficiency.

Because of the different roles of men and women in society and family, different ways of thinking and different emotions, the male and female consumers are different in purchasing power, consumption demand and purchase decision.According to the survey, we find that female consumers pay more attention to the practicality and price of products when compared with male consumers. The specific performance of this psychology is that women often choose to buy products when they buy products. Some of the subtle advantages or shortcomings of the product will attract the attention of women consumers and affect their purchasing decisions.

\section{Suggestions on Marketing of Small Pieces of Creative Ceramics in Jingdezhen}

Original designers should constantly broaden their horizons, enrich their connotations, and constantly create new ideas and innovations. In traditional and modern variations, the form of ceramic art is not only limited to traditional handmade and engraving, but also to the combination of technology, culture, philosophy or fashion. [4] Many new ideas and ideas are often produced in communication with people, such as ceramic lectures, ceramic exhibitions and ceramic creative shows. In addition, creative studio originators can also be able to share their own ways of success by holding creative sharing exchanges and visiting ceramic cultural and creative industries, and constantly renewing their thinking ways to create more innovative works.

Expand the publicity channels and intensify propaganda. Making full use of tourism resources in Jingdezhen. In 2017, the total number of tourists in Jingdezhen was 54 million 548 thousand and 700.[5] We should make full use of this resource, guide tourists to understand Jingdezhen ceramic culture, and push Jingdezhen's creative ceramics to the whole country and even the whole world.

Using the network platform to promote small creative ceramics products. Micro-blog, WeChat and other related ceramic cultural information can be published, the establishment of creative ceramics e-commerce trading platform, advertising on the mainstream website, and so on, to broaden the publicity channels.

Creative ceramic studios can establish cooperative relations with other cities, organize creative ceramics and creative ceramics exhibitions regularly, so as to integrate creative ceramics in Jingdezhen into the life of consumers.

Increasing the intellectual property protection of creative ceramic originators. The city government and the ceramic cultural and creative industry base should protect the intellectual property rights of the creative studios, set up a sound market order of creative market, carefully review the creative ceramic products entering the market, and focus on protecting ceramic creative achievements with independent intellectual property rights, setting up the management of ceramic creative symbols, [6] and strictly prohibit others to imitate the popular creative ceramic products in the market. 
Strengthening the financing support of Jingdezhen creative ceramics studio. Many sellers of creative ceramics in Jingdezhen market are investing in small cost, and the output of creative ceramics is not enough. The government agencies should provide help for creative studios in policy, increase the investment and support for the development of cultural and creative industries, and create an environment conducive to the development of the creative porcelain industry.

The main government should give full play to the function, establish the financial subsidy system, pay attention to the financial support for the ceramic creative enterprises, pay attention to the industrial guidance, and form a perfect ceramic cultural industry chain in Jingdezhen, thus effectively enhance the ability of the enterprises to fight the financial risk and enhance the ability of the financial lending of enterprises. The government needs to effectively supervise the cultural industry market and become a solid backing for ceramic culture to go to the world.

The development of creative ceramics industry in Jingdezhen should start from the perspective of market demand and combine the historical and practical values of cultural tradition,[7] actively carry out the work of cultural investment from two aspects of industrial policy and service environment, so as to promote the better, faster and more stable development of the ceramic creative industry.

\section{References}

[1] Ch.Zhang,Sh.L.Chen and D.L.Xie: China Ceramics, Vol( 2012) No.12, p.38-41. (In Chinese)

[2] G.Yang:Times Finance, Vol( 2017) No.11, p.3183. (In Chinese)

[3] Q. Liu:Journal of Ceramics, Vol 37(2016) No.5, p.572-574. (In Chinese)

[4] L.R Hu, F.Chen and B.F.Liu: Enterprise Economy, Vol (2014) No.1, p.116. (In Chinese)

[5] Information on http://www.jdz.gov.cn/xxgk/050012/050012004/20180502/b6efd0a4-fbb6-40f1-83b0-37b4b3e0 5896.html. (In Chinese)

[6] L.Q.Wang.Study on the operation strategy of Jingdezhen ceramic creative products market(MS. East China University, China 2015) , p.28. (In Chinese)

[7] B.F.Liu, L.R Hu and Y.C.Chen: Enterprise Economy, Vol (2014) No.8, p121. (In Chinese) 